\title{
Well Differentiated Prostate Adenocarcinoma
}

National Cancer Institute

\section{Source}

National Cancer Institute. Well Differentiated Prostate Adenocarcinoma. NCI Thesaurus.

Code C27905.

An invasive prostate adenocarcinoma characterized by the presence of well

differentiated malignant glandular epithelial components. 